\title{
Neuregulin-1 Protects Against Doxorubicin-Induced Apoptosis in Cardiomyocytes Through an Akt-Dependent Pathway
}

\author{
T. AN $^{1^{*}}$, Y. ZHANG ${ }^{1^{*}}$, Y. HUANG, R. ZHANG, S. YIN, X. GUO, Y. WANG, C. ZOU, \\ B. WEI, R. LV, Q. ZHOU, J. ZHANG \\ * These authors contributed equally.
}

${ }^{1}$ Heart Failure Center, State Key Laboratory of Cardiovascular Diseases, Fuwai Hospital, National Center for Cardiovascular Disease, Chinese Academy of Medical Sciences and Peking Union Medical College, Beijing, China

Received January 22, 2013

Accepted February 28, 2013

On-line April 16, 2013

\section{Summary}

In previous studies, it has been shown that recombinant human neuregulin-1(rhNRG-1) is capable of improving the survival rate in animal models of doxorubicin (DOX)-induced cardiomyopathy; however, the underlying mechanism of this phenomenon remains unknown. In this study, the role of rhNRG-1 in attenuating doxorubicin-induce apoptosis is confirmed. Neonatal rat ventricular myocytes (NRVMs) were subjected to various treatments, in order to both induce apoptosis and determine the effects of rhNRG-1 on the process. Activation of apoptosis was determined by observing increases in the protein levels of classic apoptosis markers (including cleaved caspase-3, cytochrome c, $\mathrm{BCl}-2, \mathrm{BAX}$ and terminal deoxynucleotidyl transferase-mediated deoxyuridine triphosphate nick-end labeling (TUNEL) staining). The activation of Akt was detected by means of western blot analysis. The study results showed that doxorubicin increased the number of TUNEL positive cells, as well as the protein levels of cleaved caspase- 3 and cytochrome c, and reduced the ratio of $\mathrm{Bcl}-2 / B a x$. However, all of these effects were markedly antagonized by pretreament with rhNRG-1. It was then further demonstrated that the effects of rhNRG-1 could be blocked by the phosphoinositole-3-kinase inhibitor LY294002, indicating the involvement of the Akt process in mediating the process. RhNRG-1 is a potent inhibitor of doxorubicin-induced apoptosis, which acts through the PI3K-Akt pathway. RhNRG-1 is a novel therapeutic drug which may be effective in preventing further damage from occurring in DOX-induced damaged myocardium.

\section{Key words}

Neuregulin • Doxorubicin • Apoptosis • Cardiomyocyte • Akt

\section{Corresponding author}

J. Zhang, Heart Failure Center, Cardiovascular Institute and Fuwai Hospital, Chinese Academy of Medical Sciences and Peking Union Medical College, 167 Beilishilu, Beijing 100037, China. Fax: 86-10-88396180. E-mail: Fwzhangjian62@163.com

\section{Introduction}

Doxorubicin (DOX) is an effective antineoplastic drug, and is frequently used in the treatment of hematologic and solid tumors, such as leukemia, breast cancer and sarcoma. However, the drug's clinical benefit is limited by its cardiotoxicity (Singal et al. 1998, Swain et al. 2003). DOX-induced cardiomyopathy is characterized by irreversible left ventricular dysfunction and congestive heart failure with a poor prognosis (Bristow et al. 1978, Takemura et al. 2007). Nevertheless, to date, researchers and scientists have attempted a variety of approaches aimed at preventing the deleterious action of doxorubicin, but presently the ability of these treatments to protect the heart from damage remains limited (Takemura et al. 2007). Dexrazoxane is the only well established and clinically approved cardioprotectant against ANT cardiotoxicity (Popelova et al. 2009, Sterba et al. 2013). Therefore, the development of more therapies which may be used to prevent and/or treat the cardiotoxicity of doxorubicin remains a critical issue in both cardiology and oncology.

Neuregulin (NRG)-1, a member of the neuregulin family, is expressed in many cell types and organs, including the heart. Neuregulin-1/ErbB signaling 
is essential for embryonic cardiac development. Postnatal conditional ErbB2-deficiency in cardiomyocytes may result in severe cardiomyopathy and enhanced myocyte susceptibility for DOX-induced death (Crone et al. 2002, Ozcelik et al. 2002). There are at least 31 NRG-1 isoforms derived from the NRG-1 gene which are produced by utilizing different promoters and alternative splicing, and different groups use different ligands (Fuller et al. 2008). Among these isoforms, recombinant human neuregulin-1 (rhNRG-1, a component of NRG-1) is a 61-amino-acid peptide containing an EGF-like domain, the domain which is necessary for ErbB2/ErbB4 activation. The authors of this study previously reported that rhNRG-1 is capable of improving cardiac function in patients suffering from congestive heart failure (CHF), with significant increases in left ventricular (LV) ejection fraction (LVEF). Treatment has also decreased end systolic and diastolic volume (ESV and EDV, respectively) (Gao et al. 2010), demonstrating a beneficial effect on pathological remodeling. It has also been reported that rhNRG-1 is capable of activating Erb2/4 heterodimerization, thus improving cardiac function and survival in animal models of doxorubicininduced cardiomyopathy (Liu et al. 2006). However, the underlying molecular mechanism has yet to be defined. Akt is known to regulate many survival pathways of the cardiac cells (Shiraishi et al. 2004). Recent studies have provided evidence that the anti-apoptotic effects of rhNRG- 1 are at least partially mediated by the alteration of PI3K/Akt signaling pathway during $\mathrm{H}_{2} \mathrm{O}_{2}$-induced cardiomyocyte apoptosis (Jie et al. 2012), as well as ischemia/reperfusion injury in rat hearts (Fang et al. 2010). However, whether or not rhNRG-1 is able to protect cardiomyocytes from DOX-induced apoptosis through the PI3K/Akt pathway has yet to be thoroughly investigated.

In view of this, the authors of this paper postulate that the pretreatment of rhNRG-1 possesses protective effects against DOX-induced injury in cardiomyocytes, and the activation of PI3K/Akt pathway occurs during the process.

\section{Materials and Methods}

\section{Materials}

The RhNRG-1 samples were kindly offered by Professor Zhou of Zensun Sci \& Tech Ltd. (Shanghai, China), and doxorubicin (DOX) was obtained from Sigma-Aldrich (St. Louis, MO, USA). The terminal deoxynucleotidyl transferase biotin-dUTP nick end labeling (TUNEL) staining kit was purchased from Roche Diagnostic (Mannheim Germany). LY294002 and primary antibodies against cleaved caspase-3 (catalog No. \#9664), Bcl-2 (catalog No. \#2870), Bax (catalog No. \#2772), cytochrome c (catalog No. \#4272), phosphoAkt (catalog No. \#4060), Akt (catalog No. \#4685) and $\beta$-actin (catalog No. \#4970) were obtained from Cell Signaling Technology (Danvers, MA, USA). Horseradish peroxidase(HRP)-conjugated secondary antibodies were purchased from Beyotime (Beijing, China).

\section{Cell culture}

Neonatal rat ventricular myocytes (NRVMs) were cultured from two-day-old SD rats, as previously described (Tan et al. 2008). The protocol was approved by the Fuwai Hospital Animal Care and Use Committee, in accordance with the "Guide for the Care and Use of Laboratory Animals" published by the US National Institute of Health (National Institute of Health Publication No. 85-23, revised 1996). In brief, the hearts were washed, the atria removed and the ventricles minced after dissection in HEPES-buffered saline solution containing $130 \mathrm{mM} \mathrm{NaCl}, 3 \mathrm{mM} \mathrm{KCl}, 1 \mathrm{mM} \mathrm{NaH} \mathrm{PO}_{4}$, $4 \mathrm{mM}$ glucose, and $20 \mathrm{mM}$ HEPES (the $\mathrm{pH}$ of which was adjusted to 7.35 with $\mathrm{NaOH}$ ). The tissues were dispersed in a series of incubations at $37{ }^{\circ} \mathrm{C}$ in HEPES-buffered saline solution containing $1.2 \mathrm{mg} \mathrm{ml}^{-1}$ pancreatin and $0.14 \mathrm{mg} \mathrm{ml}^{-1}$ collagenase (Worthington, NJ, USA). After centrifugation, the cells were resuspended in a DMEM/F12 medium (GIBCO, Grand Island, NY, USA) containing $5 \%$ (vol/vol) heat-inactivated horse serum, $0.1 \mathrm{mM}$ ascorbate, insulin-transferring sodium selenite media supplement, $100 \mathrm{U} \mathrm{ml}^{-1}$ penicillin, $100 \mu \mathrm{g} \mathrm{ml} \mathrm{ml}^{-1}$ streptomycin, and $0.1 \mathrm{mM}$ bromodeoxyuridine. The dissociated cells were preplated at $37^{\circ} \mathrm{C}$ for $1 \mathrm{~h}$, then diluted to $1 \times 106$ cells ml$^{-1}$ and, plated in culture dishes coated with $10 \mu \mathrm{g} \mathrm{ml}^{-1}$ laminin.

\section{Cell viability analysis}

Cell viability was determined by the MTT assay (Beyotime, Beijing, China). The cells were seeded at $1 \times 10^{4}$ cells/well in 96-well plates. After drug treatment, $20 \mu \mathrm{l}$ of $5 \mathrm{mg} / \mathrm{ml}$ MTT solution was added to each well, and incubated for $4 \mathrm{~h}$. The supernatants were aspirated, and the formazan crystals in each well were dissolved in $150 \mu \mathrm{l}$ of dimethyl sulfoxide. The absorbance was measured at $570 \mathrm{~nm}$ using a micro plate reader (Spectrafluor, TECAN, sunrise, Austria). 


\section{TUNEL assay}

Apoptosis was determined by TUNEL assay (Roche), according to the manufacturer's instructions. The cells were visualized by a laser confocal microscope (Zeiss LSM 510 META, Berlin, Germany). The apoptotic cells were counted among at least 100 cells from four randomly selected fields in each sample, and expressed as a percentage of the total number of cells.

\section{Western blot analysis}

After the designated treatment was performed, cells from each group were lysed using RIPA buffer containing $20 \mathrm{~mm}$ Tris- $\mathrm{HCl}$ (pH 7.4), $150 \mathrm{~mm} \mathrm{NaCl}, 1 \%$ Nonider P-40, $0.5 \%$ sodium deoxycholate, $0.1 \%$ SDS, $0.004 \%$ sodium azide, $1 \%$ PMSF, $1 \%$ sodium orthovanadate, and $1 \%$ protease inhibitor cocktail at $4{ }^{\circ} \mathrm{C}$. The lysate was cleared by 10 -min centrifugation at $4{ }^{\circ} \mathrm{C}$ and $12000 \times \mathrm{g}$, after which the supernates were collected. Protein concentration was determined using a bicinchoninic acid assay. Proteins $(100 \mu \mathrm{g})$ were subjected to $12 \%$ SDS-PAGE and transferred to nitrocellulose membranes. The membranes were blocked for $1 \mathrm{~h}$ in $1 \%$ skim milk and incubated overnight at $4{ }^{\circ} \mathrm{C}$ with the primary antibodies. The membranes were then probed using horseradish peroxidase-conjugated goat anti-rabbit IgG. Antigen-antibody complexes were detected by means of enhanced chemiluminescence (American Biosciences Crop, NJ, USA). The protein expression levels were determined by analyzing the signals captured on the nitrocellulose membranes using a Chemi-doc image analyzer (Bio-Rad, USA).

\section{Statistical analysis}

The study results are expressed as mean \pm SEM. The statistical significance was calculated by one-way analysis of variance, followed by Tukey's post-hoc tests for multiple comparisons. Two groups were evaluated by means of Student's $\mathrm{t}$ test. $\mathrm{P}<0.05$ was considered statistically significant. All analyses were performed using SPSS software (v13.0, Chicago, IL, USA).

\section{Results}

Effects of rhNRG-1 on doxorubicin-induced cardiomyocyte apoptosis

First, the MTT assay was used to assess the cell viability of the NRVMs. It was shown that the decrease in cell viability induced by DOX insult was significantly improved by the rhNRG-1 treatment. As shown in Figure
1A, after DOX $(1 \mu \mathrm{M})$ treatment for $24 \mathrm{~h}$, cell viability decreased significantly (by $55 \%$ ) compared with the control. The pretreatment of rhNRG-1 (10, 100, 1000 $\mathrm{ng} / \mathrm{ml}$ ) attenuated the DOX-induced decrease in cell viabilities in a concentration dependent manner. It was observed that $1000 \mathrm{ng} / \mathrm{ml}$ rhNRG-1 shows clear protection against DOX-induced decreased cell viability in NRVMs. Therefore, $1000 \mathrm{ng} / \mathrm{ml}$ rhNRG-1 was chosen for the subsequent experiments.

The influence of the rhNRG-1 on apoptotic markers, such as cleaved caspase- 3 and cytochrome c, was further evaluated by means of western blotting analyses, as shown in Figure 1B. The cleaved caspase-3 (Fig. 1C) and cytosol cytochrome c (Fig. 1D) were greatly elevated in cells treated with $1 \mu \mathrm{M}$ for $24 \mathrm{~h}$. Pre-treatment with rhNRG-1 at $1000 \mathrm{ng} / \mathrm{ml}$ for $1 \mathrm{~h}$ significantly reduced the quantity of cleaved caspase- 3 and cytosol cytochrome c, as compared with that in doxorubicin-treated alone cells. These results indicate that the preatment of rhNRG-1 inhibited DOX-induced apoptosis.

\section{Effects of rhNRG-1 on phospho-Akt in NRVMs}

Akt is known to have an inhibitory effect on apoptosis in several cell types (Matsui et al. 2001). In order to determine the effects of rhNRG-1 on Akt phosphorylation in NRVMs, phospho-Akt (for serine 473) was detected (Fig. 2). Western blotting analysis showed that DOX downregulated the levels of phospho-Akt in NRVMs, but these levels were restored to the above basal levels in cells pretreated with rhNRG-1. In order to determine whether or not the restoration of Akt phophorylation by rhNRG-1 is involved in the signaling of PI3K, the effect of its specific inhibitor LY294002 was used. rhNRG-1-induced restoration of Akt phosphorylation was completely inhibited by LY294002 (10 $\mu \mathrm{M})$.

Role of Akt in the protective effect of rhNRG-1 on doxorubicin-induced NRVMs apoptosis

In order to determine whether or not the rhNRG1-indeced Akt activation is responsible for its cell protective effect, the effect of blocking the PI3K-Akt pathway on the ability of rhNRG-1-induced cell protection was determined. As shown in Figure 3, in the presence of the PI3K specific inhibitor LY294002, the protective effects of rhNRG-1 on DOX-induced cell injury were completely reversed. Increased cell apoptosis was detected by a fivefold increase in the number of TUNEL-positive myocytes (Fig. 3A, B) and the western 


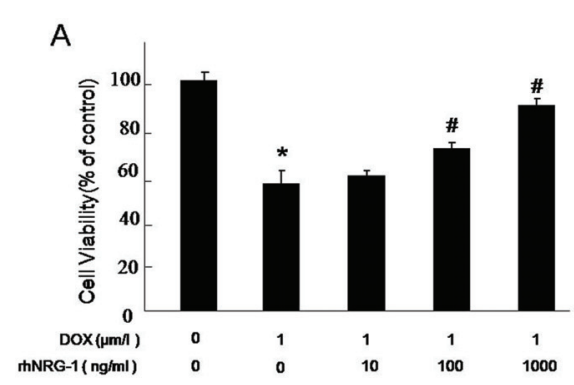

B

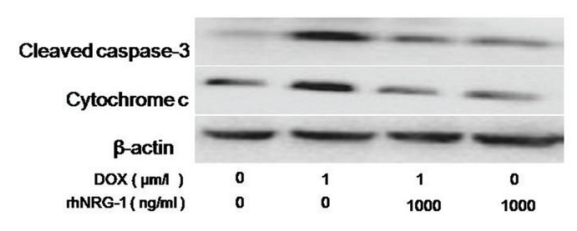

C

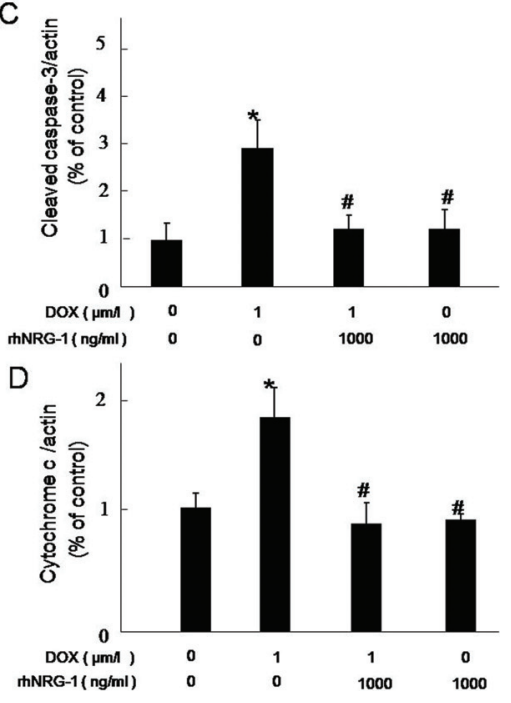

Fig. 1. Effects of rhNRG-1 on doxorubicin-induced cardiomyocyte apoptosis. NRVMs were pretreated with the indicated rhNRG-1 concentrations for $1 \mathrm{~h}$, followed by $24 \mathrm{~h}$ of DOX $(1 \mu \mathrm{M})$ treatment. A: Cell viability was determined by MTT assay. B: Western blotting was performed with the specific antibody against cleaved caspase- 3 and cytochrome c, and $\beta$-actin was used as a loading control. C: Densitometric analysis of cleaved caspase-3. D: Densitometric analysis of cytochrome c. Error bars represent mean \pm SEM. $* P<0.05$ vs. control, $\# P<0.05$ vs. DOX alone, $(n=4)$. DOX: doxorubicin; NRVMs: neonatal rat ventricular myocytes; rhNRG-1: recombinant human neuregulin-1.

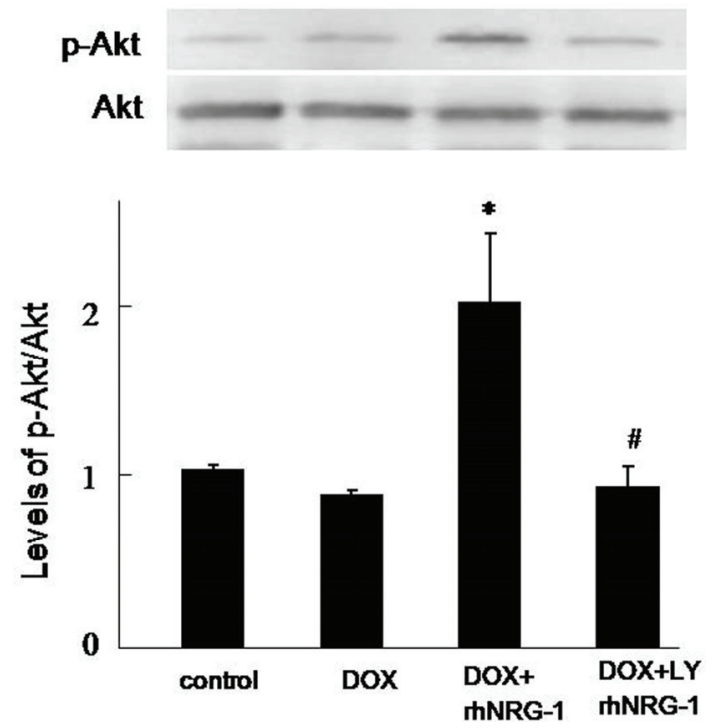

Fig. 2. Effects of rhNRG-1 on phosphor-Akt in cardiomyocytes. NRVMs were treated with DOX $(1 \mu \mathrm{M})$ with or without a $1 \mathrm{~h}$, LY294002 $(10 \mu \mathrm{M})$ or rhNRG-1 $(1000 \mathrm{ng} / \mathrm{ml})$ pretreatment. The levels of p-Akt and Akt were detected by western blotting. Error bars represent mean \pm SEM. $* \mathrm{P}<0.05$ vs. control, \#P<0.05 vs. DOX alone, $(n=6)$. DOX: doxorubicin; NRVMs: neonatal rat ventricular myocytes; rhNRG-1: recombinant human neuregulin-1.

blotting analysis of ration of Bcl-2/Bax (Fig. 3C). Decreased cell viability was determined via MTT assay (Fig. 3D). Therefore, it was shown that the PI3K/Akt signaling pathway is indeed involved in the anti-apoptotic effect of rhNRG-1.

\section{Discussion}

It has previously been shown that doxorubicin significantly reduces NRG-1 protein expression in the heart (Horie et al. 2010). Based upon work in isolated cell systems, current data indicates that a number of processes are regulated by Nrg-1/ErbB signaling, including cell growth and survival (Zhao et al. 1998), as well as myofilament structure and organization (Sawyer et al. 2002, Pentassuglia et al. 2007), myocyte-matrix coupling (Kuramochi et al. 2006) and angiogenesis (Russell et al. 1999). Until now, 31 members of spliced variants of NRG-1 have been identified. Their isoforms differ in their tissue-specific expression patterns and their biological activities, thereby contributing to the great diversity of the functions of NRG1 and different groups have used different ligands. In this study rhNRG-1 was focused on, due to the fact that rhNRG-1 was administered by IV to clinically relevant chronic rat models of doxorubicin-induced cardiomyopathy, and cardiac function and survival were improved (Liu et al. 2006). And it is the only one whose safety and efficacy have been assessed in chronic heart failure patients (Gao et al. 2010). The present study shows for the first time that rhNRG-1 attenuates DOX-induced apoptosis via PI3K/Akt signaling in cardiomyocytes.

It has previously been shown that the ability of DEX to prevent the triggering of multiple apoptotic pathways may account for its high efficacy in the prevention of ANT-induced cardiotoxicity (Popelova et al. 2009). So apoptosis plays an important role in DOXinduced cardiotoxicity. It has been demonstrated that Bcl-2 family members, such as Bcl-2 and Bax, and caspase family members, especially caspase-3, play important roles in apoptotic cell death. The proapoptotic members of the Bcl-2 family of proteins enhance the permeability of the mitochondrial outer membrane. An increase in outer membrane permeability results in a protein release from the intermembrane space to the 
A

DAPI

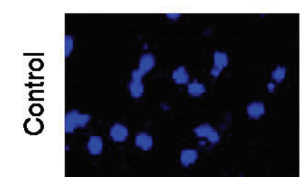

خ
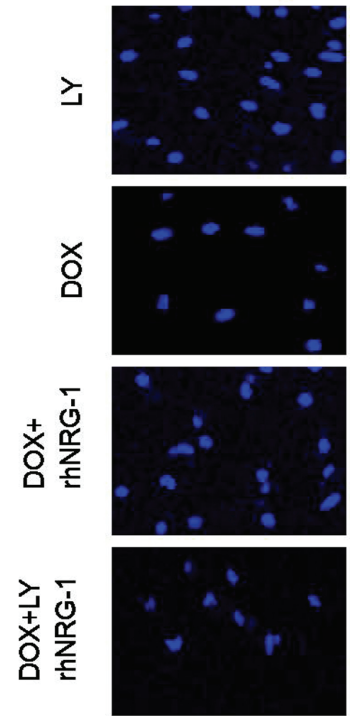

TUNEL
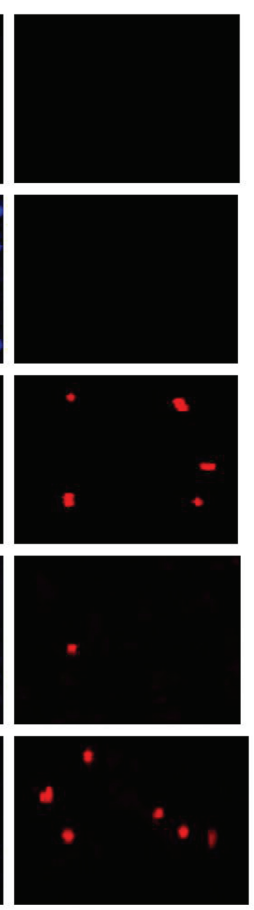

$\mathrm{B}$
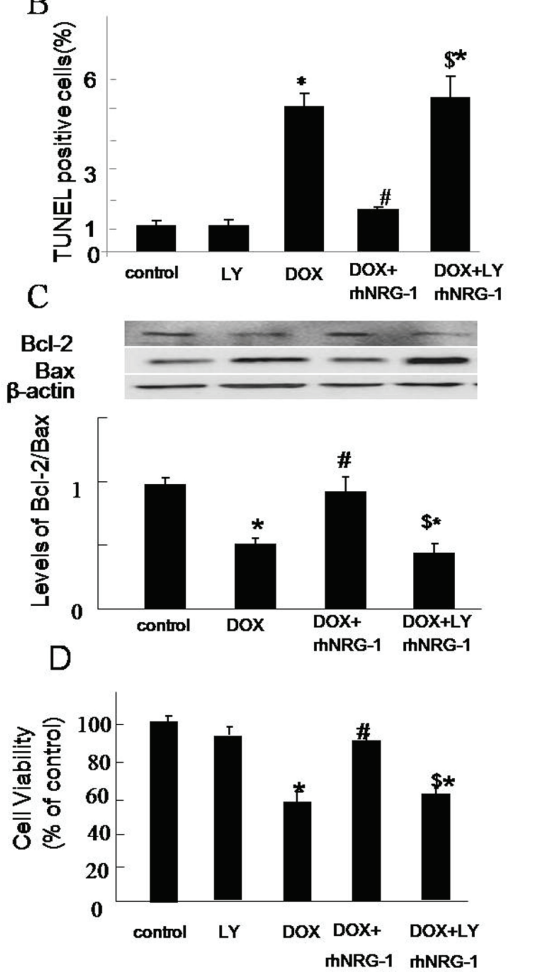

Fig. 3. Role of Akt in the protective effect of rhNRG-1 on doxorubicininduced NRVM apoptosis. NRVMs were pre-incubated with $10 \mu \mathrm{M}$ LY294002 for $1 \mathrm{~h}$, then pretreated with rhNRG-1 $(1000 \mathrm{ng} / \mathrm{ml})$ for $1 \mathrm{~h}$, followed by DOX $(1 \mu \mathrm{M})$ for $24 \mathrm{~h}$. A and B: The decrease in the ratio of TUNEL-positive cells to total cells. C: The western blotting results showed the decreased ratio of $\mathrm{Bcl}-2 / \mathrm{Bax}$. D: Cell viability was determined by MTT assay. Error bars represent mean \pm SEM. ${ }^{*} \mathrm{P}<0.05$ vs. control, \#P<0.05 vs. DOX alone, $\$ \mathrm{P}<0.05$ vs. DOX+rhNRG-1, $(n=3)$. DOX: doxorubicin; NRVMs: neonatal rat ventricular myocytes; rhNRG-1: recombinant human neuregulin-1. cytoplasm, including apoptogenic molecules such as cytochrome c. Cytochrome $\mathrm{c}$ then binds to apoptotic protease activating factor-1 and triggers oligomerization. This complex, known as an apoptosome, recruits and cleaves procaspase- 9 into the active enzyme, in turn activating caspase-3, which is directly responsible for cell death (Nishida et al. 2008). In order to examine the underlying mechanism of antiapoptotic of rhNRG-1, the respective expressions of Bcl-2, Bax, cytochrome $\mathrm{c}$ and cleaved caspase- 3 were examined. The results show that rhNRG-1 upregulated the ration of Bcl-2/bax expression and decreased the protein levels of cytochrome c. It was also found that, under DOX treatment, the activity of caspase-3 was increased, and rhNRG-1 significantly reduced the activation. All of these observations are consistent with the results of the TUNEL assay.

Neuregulins transmit their signals to target cells by interacting with transmembrane tyrosine kinase receptors of the ErbB family. Receptor-ligand interaction induces the heterodimerization of receptor monomers, which in turn results in the activation of intracellular signaling cascades and the induction of cellular responses including proliferation, migration, differentiation, and survival or apoptosis. Under physiological conditions, NRG-1 binds to ErbB3 or ErbB4, which results in the formation of ErbB2/ErbB3 or ErbB2/ErbB4 heterodimers. The main receptors for NRG-1 signaling in the heart are ErbB-2 and ErbB-4. Following NRG-1activated ErbB receptor dimerization, phosphorylation of tyrosine residues in the cytoplasmic domain of the receptor creates docking sites for various adaptor proteins such as Shc, Grb2, and the regulatory subunit of phosphoinositide-3-kinase (PI3-kinase). These, in turn, activate their downstream effectors. And the phosphoinositide 3-kinase(PI3K)-Akt signaling pathway is one of the important signal transtruction pathways regulating cardiac growth, myocardial angiogenesis, glucose metabolism, and cell death in cardiomyocytes (Chaanine et al. 2011). Various growth factors and cellular stress activate Akt through phosphorylation of serine 473 resides. Once activated, Akt proceeds to phosphorylate its downstream targets, in various subcellular locations, contributing to its anti-apoptotic effects (Matsui et al. 2005). As other types of NRG-1 were previously reported (Bian et al. 2009), rhNRG-1induced activation of Akt. In order to explore whether or not the protective effects of rhNRG-1 are associated with the PI3K/Akt pathway, the PI3K specific inhibitor LY294002 was used. Co-treatment of LY294002 and rhNRG-1 abolished the cardioprotective effects of rhNRG-1, which rhNRG-1 alone is not capable of. These results suggest that rhNRG-1 induces cardioprotective effects through the activation of the Akt pathway.

It must be acknowledged that this study has 
several limitations. First, the role of alternative ErbB2/ErbB4 intracellular signaling pathways in the protective effects of rhNRG-1 (Odiete et al. 2012) were not explored. Further studies are required in the future. In addition, the NRVMs differ from the adult ones, as NRG-1 is capable of inducing tyrosine phosphorylation of receptors ErbB2 and ErbB4 in both neonatal and adult cardiomyocytes, and is quite prominent in neonatal myocytes (Zhao et al. 1998). However, in the present study, the protective effects of rhNRG-1 were not detected in the adult cardiomyocytes. Therefore, the role of rhNRG-1 in adult cardiomyocytes is an issue which requires elucidation in the near future.

In conclusion, the present study strongly demonstrated that rhNRG-1 protects NRVM from DOXinduced apoptosis, and that rhNRG-1 may potentially be used to treat DOX-induced cardiotoxicity.

\section{Conflict of Interest}

There is no conflict of interest.

\section{Acknowledgements}

The authors would like to thank Prof. Jeffrey Robbins, Division of Molecular Cardiovascular Biology, Children's Hospital Research Foundation, Cincinnati, for editing the manuscript, as well as Zensun Sci \& Tech Ltd. (Shanghai, China), for providing the neuregulin-1.

\section{References}

BIAN Y, SUN M, SILVER M, HO KK, MARCHIONNI MA, CAGGIANO AO, STONE JR, AMENDE I, HAMPTON TG, MORGAN JP, YAN X: Neuregulin-1 attenuated doxorubicin-induced decrease in cardiac troponins. Am J Physiol Heart Circ Physiol 297: H1974-H1983, 2009.

BRISTOW MR, BILLINGHAM ME, MASON JW, DANIELS JR: Clinical spectrum of anthracycline antibiotic cardiotoxicity. Cancer Treat Rep 62: 873-879, 1978.

CHAANINE AH, HAJJAR RJ: AKT signalling in the failing heart. Eur J Heart Fail 13: 825-829, 2011.

CRONE SA, ZHAO YY, FAN L, GU Y, MINAMISAWA S, LIU Y, PETERSON KL, CHEN J, KAHN R, CONDORELLI G, ROSS J JR, CHIEN KR, LEE KF: ErbB2 is essential in the prevention of dilated cardiomyopathy. Nat Med 8: 459-465, 2002.

FANG SJ, WU XS, HAN ZH, ZHANG XX, WANG CM, LI XY, LU LQ, ZHANG JL: Neuregulin-1 preconditioning protects the heart against ischemia/reperfusion injury through a PI3K/Akt-dependent mechanism. Chin Med J (Engl) 123: 3597-3604, 2010.

FULLER SJ, SIVARAJAH K, SUGDEN PH: ErbB receptors, their ligands, and the consequences of their activation and inhibition in the myocardium. J Mol Cell Cardiol 44: 831-854, 2008.

GAO R, ZHANG J, CHENG L, WU X, DONG W, YANG X, LI T, LIU X, XU Y, LI X, ZHOU M: A Phase II, randomized, double-blind, multicenter, based on standard therapy, placebo-controlled study of the efficacy and safety of recombinant human neuregulin-1 in patients with chronic heart failure. J Am Coll Cardiol 55: $1907-$ $1914,2010$.

HORIE T, ONO K, NISHI H, NAGAO K, KINOSHITA M, WATANABE S, KUWABARA Y, NAKASHIMA Y, TAKANABE-MORI R, NISHI E, HASEGAWA K, KITA T, KIMURA T: Acute doxorubicin cardiotoxicity is associated with miR-146a-induced inhibition of the neuregulin-ErbB pathway. Cardiovasc Res 87: 656-664, 2010.

JIE B, ZHANG X, WU X, XIN Y, LIU Y, GUO Y: Neuregulin-1 suppresses cardiomyocyte apoptosis by activating PI3K/Akt and inhibiting mitochondrial permeability transition pore. Mol Cell Biochem 370: 35-43, 2012.

KURAMOCHI Y, GUO X, SAWYER DB: Neuregulin activates erbB2-dependent src/FAK signaling and cytoskeletal remodeling in isolated adult rat cardiac myocytes. $J$ Mol Cell Cardiol 41: 228-235, 2006.

LIU X, GU X, LI Z, LI X, LI H, CHANG J, CHEN P, JIN J, XI B, CHEN D, LAI D, GRAHAM R M, ZHOU M: Neuregulin-1/erbB-activation improves cardiac function and survival in models of ischemic, dilated, and viral cardiomyopathy. J Am Coll Cardiol 48: 1438-1447, 2006.

MATSUI T, ROSENZWEIG A: Convergent signal transduction pathways controlling cardiomyocyte survival and function: the role of PI 3-kinase and Akt. J Mol Cell Cardiol 38: 63-71, 2005. 
MATSUI T, TAO J, DEL MONTE F, LEE KH, LI L, PICARD M, FORCE TL, FRANKE TF, HAJJAR RJ, ROSENZWEIG A: Akt activation preserves cardiac function and prevents injury after transient cardiac ischemia in vivo. Circulation 104: 330-335, 2001.

NISHIDA K, YAMAGUCHI O, OTSU K: Crosstalk between autophagy and apoptosis in heart disease. Circ Res 103: 343-351, 2008.

ODIETE O, HILL MF, SAWYER DB: Neuregulin in cardiovascular development and disease. Circ Res 111: 1376$1385,2012$.

OZCELIK C, ERDMANN B, PILZ B, WETTSCHURECK N, BRITSCH S, HUBNER N, CHIEN KR, BIRCHMEIER C, GARRATT AN: Conditional mutation of the ErbB2 (HER2) receptor in cardiomyocytes leads to dilated cardiomyopathy. Proc Natl Acad Sci USA 99: 8880-8885, 2002.

PENTASSUGLIA L, TIMOLATI F, SEIFRIZ F, ABUDUKADIER K, SUTER TM, ZUPPINGER C: Inhibition of ErbB2/neuregulin signaling augments paclitaxel-induced cardiotoxicity in adult ventricular myocytes. Exp Cell Res 313: 1588-1601, 2007.

POPELOVA O, STERBA M, HASKOVA P, SIMUNEK T, HROCH M, GUNCOVA I, NACHTIGAL P, ADAMCOVA M, GERSL V, MAZUROVA Y: Dexrazoxane-afforded protection against chronic anthracycline cardiotoxicity in vivo: effective rescue of cardiomyocytes from apoptotic cell death. Br J Cancer 101: 792-802, 2009.

RUSSELL KS, STERN DF, POLVERINI PJ, BENDER JR: Neuregulin activation of ErbB receptors in vascular endothelium leads to angiogenesis. Am J Physiol 277: H2205-H2211, 1999.

SAWYER DB, ZUPPINGER C, MILLER TA, EPPENBERGER HM, SUTER TM: Modulation of anthracyclineinduced myofibrillar disarray in rat ventricular myocytes by neuregulin-1beta and anti-erbB2: potential mechanism for trastuzumab-induced cardiotoxicity. Circulation 105: 1551-1554, 2002.

SHIRAISHI I, MELENDEZ J, AHN Y, SKAVDAHL M, MURPHY E, WELCH S, SCHAEFER E, WALSH K, ROSENZWEIG A, TORELLA D, NURZYNSKA D, KAJSTURA J, LERI A, ANVERSA P, SUSSMAN MA: Nuclear targeting of Akt enhances kinase activity and survival of cardiomyocytes. Circ Res 94: 884-891, 2004.

SINGAL PK, ILISKOVIC N: Doxorubicin-induced cardiomyopathy. N Engl J Med 339: 900-905, 1998.

STERBA M, POPELOVA O, VAVROVA A, JIRKOVSKY E, KOVARIKOVA P, GERSL V, SIMUNEK T: Oxidative stress, redox signaling, and metal chelation in anthracycline cardiotoxicity and pharmacological cardioprotection. Antioxid Redox Signal 18: 899-929, 2013.

SWAIN SM, WHALEY FS, EWER MS: Congestive heart failure in patients treated with doxorubicin: a retrospective analysis of three trials. Cancer 97: 2869-2879, 2003.

TAKEMURA G, FUJIWARA H: Doxorubicin-induced cardiomyopathy from the cardiotoxic mechanisms to management. Prog Cardiovasc Dis 49: 330-352, 2007.

TAN WQ, WANG K, LV DY, LI PF: Foxo3a inhibits cardiomyocyte hypertrophy through transactivating catalase. J Biol Chem 283: 29730-29739, 2008.

ZHAO YY, SAWYER DR, BALIGA RR, OPEL DJ, HAN X, MARCHIONNI MA, KELLY RA: Neuregulins promote survival and growth of cardiac myocytes. Persistence of ErbB2 and ErbB4 expression in neonatal and adult ventricular myocytes. J Biol Chem 273: 10261-10269, 1998. 